\title{
PREFACE:
}

\section{LICHENOMETRY IN SUBPOLAR ENVIRONMENTS}

Lichens are a valuable dating tool for geoscientists. They have been used for over 60 years by earth scientists and archaeologists to address a range of surface dating problems - and it would be fair to say that they are currently experiencing somewhat of a renaissance. In part, this is due to the non-destructive, inexpensive and 'eco-friendly' nature of lichenometry, which has contributed to its increased popularity as a dating technique over the past 10 years.

This volume brings together 10 papers relating to lichen growth and lichen dating in subpolar environments from both hemispheres. The more traditional term "lichenometry" is preferred to "lichenometric dating" for the title of this volume as this collection of work deals with both lichen growth measurements and lichen dating studies. The original idea behind the Special Issue was to place equal emphasis on measuring lichen growth and performing lichenometric dating - as the understanding of the former is crucial to the application of the latter. This is more difficult than it would seem, as lichenometric science crosses several disciplines. Those who use lichens to date surfaces are typically geologists and geographers; whilst those who measure and understand lichen growth are traditionally specialist biologists and ecologists. This volume aims to bring strands of these different disciplines closer together - something which should be encouraged in all aspects of the environmental and earth sciences.

The structure of this special issue is simple: the first 4 papers review or present lichen growth measurements (spanning up to 25 years!) and discuss their implications for lichenometric dating. The next 5 papers review or present lichenometric-dating studies from a range of subpolar settings. The final short paper presents a novel approach to lichenometry using lichen growth rings.

One of the aspirations of this volume is to re-assert the usefulness of lichens as natural 'phytometers' (surrogates for environmental variables or the passage of time). Furthermore, the spirit of this work is to highlight the intrinsic strength of the simpler, more traditional, lichen-dating techniques whilst exploring new avenues for research. Crucially, the biological basis for lichenometry is also explored, through a better understanding of lichen growth, lichen habitats, and competition between plants. These 10 papers serve to reinforce the importance of all these issues, whilst stressing the continued need for long-term growth rate studies to better determine the growth history of the most commonly used lichen species. 
We are grateful for the opportunity to collectively publish these results in a special issue of Geografiska Annaler for three reasons:

- Firstly, this journal has a long tradition of publishing lichenometric science. From the early 1960s up until the present-day Geografiska Annaler has published classic works and novel approaches, and remains one of the leading journals for new lichenometric work.

- Secondly, the mix of disciplines contained with this issue warranted an interdisciplinary journal with a wide readership, such as Geografiska Annaler. In combining these 10 papers into one volume it is hoped that the wider earth science community will gain access to work which might normally be published in separate specialist journals.

- Finally, Professor Wibjörn Karlén, Geografiska Annaler's outgoing editor, is widely recognised as one of the pioneers of lichenometry. His classic papers from the 1970s remain just as relevant and insightful today, and it is only fitting that he should preside over the publication of this special issue.

I am particularly grateful to all the referees who took time to provide helpful and constructive reviews of the manuscripts. I have never known reviews returned so swiftly - Graham Bench and Jan Mangerud jointly hold the record, both unbelievably returning refereed manuscripts within 24 hours! I am also grateful to Wibjörn Karlén for inviting me to edit this special issue and for his support as general editor; and also to Olga Solomina for helping get things off the ground back in January. I also thank BGS for contributing towards the cost of colour illustrations and for funding my editorial time. Richard Armstrong, James Benedict and John Matthews are the driving force behind this work - without their immense contributions to science over the last 35 years, lichenometry as we know it probably wouldn’t exist! Final thanks must go to my family, Ann, Caitlin and Jack, for putting up with me when I have been somewhat 'distracted' over the last 12 months. 